\title{
The challenges of building sustainable cities: a case study of Mauritius
}

\author{
Y. Baguant-Moonshiram ${ }^{1}$, M. Samy ${ }^{2}$ \& K. Thomas ${ }^{2}$ \\ ${ }^{1}$ University of Mauritius, Mauritius \\ ${ }^{2}$ Leeds Metropolitan University, UK
}

\begin{abstract}
Planning as an "informal activity" related to the development of estates, town and villages has been the practice since colonisation in Mauritius. However, planning as a formal responsibility of the government has been developed only since the enactment of the Town and Country Planning (TCP) Act in 1954. Therefore, urban planning can be considered to be quite recent in Mauritius. Moreover, the concept of 'sustainability' in planning is in the infancy stage in the country. In 2008, the Prime Minister announced his new, long-term vision of transforming the country into a sustainable island - "Maurice Ile Durable" (MID), the key objective of which is to make Mauritius a world model for sustainable development, particularly in the context of the Small Island Developing States. The government is also coming up with a new concept of 'Eco-Village' to make new villages which are more sustainable. But in order to do so, it is very important to find the level of sustainability of the existing towns and villages in Mauritius and to make a critical assessment of the land use planning framework in the island. Urbanisation is an important component when considering sustainable development and vice versa. Unfortunately, rapid urban development has contributed to the degradation of our ecosystem. Mauritius is a small island state where there is a limited amount of natural resources and one of the main objectives of the government is to promote Mauritius as a 'Sustainable Island State'. This paper makes a critical assessment of existing planning framework in Mauritius after evaluating other countries frameworks in order to promote effective sustainable cities in Mauritius.
\end{abstract}

Keywords: Mauritius, sustainable cities, sustainable land use planning, urbanisation, Small Island Developing States (SIDS), Maurice Ile Durable. 


\section{Introduction}

Planning as an "informal activity" related to the development of estates, town and villages has been the practice since colonisation in Mauritius (NDS [1]). However, planning as a formal responsibility of the government has been developed only since the enactment of the Town and Country Planning (TCP) Act in 1954. Therefore, urban planning can be considered to be quite recent in Mauritius.

Urbanisation is defined as a movement of people from rural to urban areas with population growth equal to urban migration. According to a report by the United Nations (2010), the ratio of urban populations rose from 13\% in 1900, to $29 \%$ in 1950 , to $50 \%$ in 2009 , and it is projected to be $69 \%$ in 2050 . Urbanisation brings many benefits, such as diversity, market efficiency, jobs, education, and health improvement (Christopher [2]) and (Glaeser [3]). It is these benefits that attract a continuous flow of people from rural to urban areas. However, due to the rapid pace of urbanisation, natural ecosystems are increasingly replaced by cities (Attwell [4]). It has been noted that urbanisation leads to many problems, such as air and water pollution, depletion of cultivated land due to urban sprawl, global climate change, and others (Li et al. [5] and Yigitcanlar [6]). These problems present barriers to achieving sustainable development.

This phenomenon is also observed in Mauritius where about $52 \%$ of the population lives in urban areas. Agricultural land is being replaced by construction and actually only $43 \%$ of the land remains under agriculture (Statistics Mauritius [7]).

\section{The existing policies/strategies in Mauritius}

\subsection{National development strategy}

The National Development Strategy is a strategy that sets out broad objectives, strategies and principles to promote an orderly organised development of the overall land resources and also lays down the criteria for an efficient allocation of land for different uses namely for the conurbation, countryside and the coast, housing, social and community facilities, industry and commerce, tourism, agriculture, forestry and natural resources, the environment and fisheries, transport and public infrastructures. The National Development Strategy has the duty to identify key issues in the town and country planning in Mauritius and thus it devises concepts, strategies and principles so as to assure that sustainable development is attained in every field. Therefore, the strategic vision of the National Development Strategy is "encouraging economic growth in the conurbation, the country side and the coast whilst maintaining and enhancing the quality of the environment and striving for a more sustainable pattern of development" (NDS [1]). 


\subsection{Outline planning schemes}

The Outline Planning Schemes, which are regional plans for a Municipal Council or District Council area, provide the framework for local authorities to plan, shape and control the use of land within their area. Outline Schemes set out broad proposals for the physical development of a planning area, including such matters as the location and extent of areas for housing, commerce and industry activities, the reservation of sites for public facilities and community facilities, proposal for new and improved roads, measures to protect the agricultural areas and areas of attractive landscape. They therefore translate the national strategy to the local level.

\subsection{Planning policy guidelines}

National Planning Policy Guidelines (NPPGs) are written statements which set out guidance on particular planning issues. Communities and Local Government determines national policies on different aspects of planning and the rules that govern the operation of the system.

\section{The Mauritian context}

The population of Mauritius is actually 1.2 million and is projected to increase by a further 160000 people by the year 2030. Also, major developments are expected in the future in the different areas (industry, infrastructure development, agriculture, tourism) and this will lead to further pressure on the existing natural resources and the environment. GDP per capita has grown by $9.8 \%$ between 1990 and 2009. Increasing consumption trends have followed on the natural resources and the fossil fuel use for the production of electricity and energy for transportation (MEO [8]).

As per the forecast of the government, 12200 hectares of land will be needed in the next ten years to cater for the increasing demands. As such, a sustainable land use planning and land management is essential (MEO [8]).

\subsection{Sustainable development in Mauritius}

In the Mauritian context, the term 'sustainability' has been used widely during the MID process and in the Green Paper [9] which is entitled 'Towards a National Policy for a Sustainable Mauritius'. However, no exact definition of the term has been given. During the wide national consultation carried out in the MID context, a range of issues were identified that relate to the conventional three dimensions of sustainability, namely the economy, environment, and social issues. Most significantly, and rather unexpectedly, a fourth one dimension, namely governance, was identified in the classification of issues. In this study, these four issues will be considered during the formulation of a framework to promote sustainable development (Green Paper [9]).

But it should be noted than until now, whenever the concept of Sustainable Island has been cited in the Mauritian context, it has been mostly related to the 
protection of the environment and most of the studies carried out till now have been focused on the environment. Even in 2008, when the Government first came up with the MID concept, it was concerned mainly with the energy sector. It was later expanded to cover other aspects of sustainable development, namely environment, education, employment and social equity (MID).

There has been a lack of studies carried out in the field of urban planning in Mauritius and little importance given to this sector. The integrated and holistic approach to planning has been sadly lacking till now. There is also a focus on the creation of 'new eco-villages' but it is important not to overlook the existing urban areas. These towns should be 're-designed' to be made more sustainable and the concepts of spatial planning alongside strategic planning should be encouraged.

Mauritius is one of the Small Island Developing States (SIDs) which are known to be more vulnerable to environmental degradation, climate change, over-exploitation of fisheries, land and sea pollutions and natural disasters compared to larger countries (UNEP [10]).

The small size and the geographical isolation of Mauritius, make it extremely vulnerable to natural disasters, food security and rising fossil fuel cost (Green Paper [9]). Mauritius depends highly on imports to meet its needs, for instance: $70 \%$ of the food consumed is imported (Food Security Strategic Plan for 2008 to 2011,2008 ) and fossil fuels which are also imported, meet $82 \%$ of its primary energy requirements (SCP [11]). It therefore, might not have sufficient resources to resist post-disaster effects which may occur in the future. Proper planning and sustainability interventions will certainly help to mitigate these effects.

\subsection{Maurice Ile Durable (MID)}

In 2008, the Maurice Ile Durable (MID) concept was launched with a long-term vision aimed at promoting sustainable development in Mauritius. The Maurice Ile Durable Fund is now under the aegis of the Ministry of Environment and Sustainable Development. Its main objective was to make Mauritius less dependent on fossil fuels for energy generation. However, according to the latest release the 'Green Paper', it is now open to the economic, social and environmental considerations and the 5Es - that is Energy, Environment, Employment, Education and Equity. The 5Es have been broken down further into several themes.

\subsubsection{Indicators for Mauritius}

A survey was carried out among the ministries, local authorities, NGOs, different sectors such as the construction, fisheries and health sectors, and academia and students. The overall result of the survey showing themes (or indicators) which are important for sustainable development in Mauritius is shown in figure 1 (Green Paper [9]). 

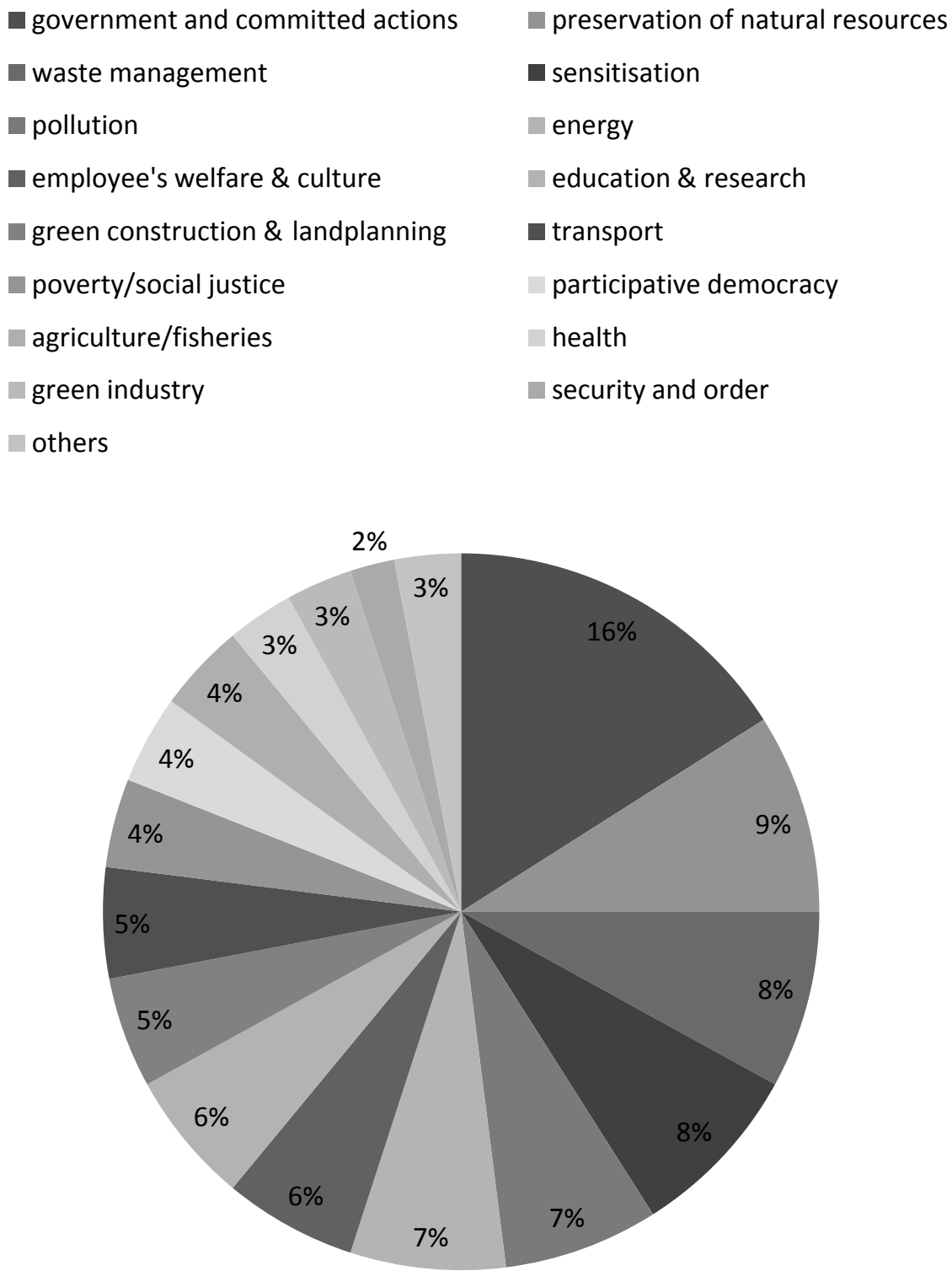

Figure 1: Percentage breakdown of overall main themes (source: Green Paper 2011). 


\section{Government and committed actions}

The most important issue which has been determined is the promotion of sustainable development by the Government (Green Paper [9]). The Government has a critical role of establishing laws, regulations and legislations. It must also ensure that there is a clear commitment from the top of the government to the bottom, through all public bodies (House of Commons Environmental Audit Committee, 2009).

Moreover, public participation (bottom up approach) in decision making is important as it prevents problems from cropping up during the implementation phase. However, much importance is not given to it in Mauritius. An example of a project in which the public was not involved in decision making is the Pont Fer Bypass - as a result, the inhabitants of Valentina and Petit Camp have to travel longer distances to reach their villages. A temporary solution has been found, the bypass will be open only during peak hours (15h45 till 18h30); a permanent solution is yet to be found. This problem could have been avoided by the use of the bottom up approach.

\section{Weaknesses in the planning sector in Mauritius}

It was noted, after consultation with stakeholders that there are several weaknesses in the planning sector:

- Top-down approach

o Decisions are made without consultation with the main stakeholders. Community participation is practically nonexistent in the formulation of decisions or the preparation of plans/guidelines. Thus, the implementation and the enforcement of these plans/guidelines.

- Legislation:

o Some legislation are very old and outdated: example the Town and Country Planning Act of 1954 and penalties are considered to be too minimal and are not deterrent

o There is a fragmentation of legislation and authorities and this is a drawback in implementation and enforcement of policies. As such there is a lack of holistic approach and harmonisation.

o The strategies of the National Development Strategy Scheme, which promote sustainable development, are not implemented.

o Legislations exist but there is a lack of follow up in the implementation and enforcement mechanism. 
- $\quad$ Lack of resources available especially concerning the enforcement and monitoring of existing strategies and policies. Authorities are always short staffed or under equipped and this is a major issue in the planning framework in Mauritius.

\section{Conclusion}

The challenges of sustainable cities are numerous in Mauritius; however these must be overcome in order to make the whole island a model for sustainability. A planning framework appropriate to the Mauritian context should be developed as Mauritius has its own specificities, resources and constraints.

\section{References}

[1] National Development Strategy Plan, Ministry of Housing, Mauritius, 2003

[2] Christopher, D., Health and urban living, Science, Volume 319, pp. 766769, 2008

[3] Glaeser, E.L., Are cities dying?, The Journal of Economic Perspective, Volume 12, pp. 139-160, 1998

[4] Attwell, K., Urban land resource and urban planting - Case studies from Denmark, Landscape and Urban Planning, Volume 52, pp. 145-163, 2000

[5] Li, F, Liu, X.S. and Hu, D., Measurement indicators and an evaluation approach for assessing urban sustainable development: A case study for China's Jining City, Landscape and Urban Planning, Volume 90, pp. 134142, 2009

[6] Yigitcanlar, T., Planning for smart urban ecosystems: Information technology applications for capacity building in environmental decision making, Theoretical and Empirical Researches in Urban Management, Volume 3, pp. 5-21, 2009

[7] Statistics Mauritius, Central Statistics Office, http://www.gov.mu/portal/ goc/cso/ei785/toc.htm

[8] Mauritius Environment Outlook Report, Ministry of Environment and Sustainable Development, 2011

[9] Green Paper, Towards a National Policy for Sustainable Development, Ministry of Environment and Sustainable Development, Mauritius, 2011

[10] United Nations Environment Programme, (UNEP), 16-20 October, Beijing, People's Republic of China, 2006

[11] National Programme on Sustainable Consumption and Production, Ministry of Environment and National Development Unit, Mauritius, 2010 